\title{
Adana ilinde önemli kültür bitkilerinde bulunan bitki paraziti nematod türleri ${ }^{1}$
}

\author{
Plant parasitic nematode species found on important cultivated plants in Adana
}

\author{
Ece B. KASAPOĞLU ${ }^{*}$
}

\author{
İ.Halil ELEKCIOĞLU²
}

\begin{abstract}
Summary
Plant parasitic nematodes which are animal organisms cause serious economic losses in cultivated plants. The total of 140 soil samples was collected for the detection of plant parasitic nematodes in Adana in 2010. Plant parasitic nematodes were identified with classical methods. 23 plant parasitic nematode species belonging to 12 genus, 8 families in the orders Tylenchida, Aphelenchida, Dorylaimida were detected. Pratylenchus zeae Graham, 1951, P. loosi Loof, 1960, P. delattrei Luc, 1958, Helicotylenchus digonicus Perry, in Perry, Darling and Thorne, 1959, Scutylenchus cylindricaudatus Ivanova, 1968, are new records for the Eastern Mediterranean Region of Turkey. Pratylenchus delattrei is recorded for the first time the nematoda fauna of Turkey. In this study, Aphelenchus avenae, Rotylenchulus macrosomus, Pratylenchus thornei, Merlinius brevidens ve Tylenchulus semipenetrans were determined as the most common species.
\end{abstract}

Key words: Plant parasitic nematodes, systematic, survey, Adana

\section{Özet}

Bitki paraziti nematodlar kültür bitkilerinde önemli ekonomik kayıplara neden olan zararlı organizmalardır. Adana'da tarım yapılan alanlarda bulunan bitki paraziti nematodların saptanması amacıyla 2010 yılında toplam 140 toprak örneği alınmıştır. Bitki paraziti nematodların türleri klasik yöntemlerle (Morfometrik karakterler) teşhis edilmiştir. Tylenchida, Aphelenchida ve Dorylaimida takımlarına ait 8 familyaya bağlı 12 cinse ait 23 bitki parazi nematod türü tespit edilmiştir. Pratylenchus zeae Graham, 1951, P. loosi Loof, 1960, P. delattrei Luc, 1958, Helicotylenchus digonicus Perry, in Perry, Darling and Thorne, 1959, Scutylenchus cylindricaudatus Ivanova, 1968, Türkiye Doğu Akdeniz Bölgesi için yeni kayıttır. Pratylenchus delattrei (Luc), Türkiye nematod faunası için yeni kayıt niteliğindedir. Bu çalışmada bulunan en yaygın türlerin Aphelenchus avenae, Rotylenchulus macrosomus, Pratylenchus thornei, Merlinius brevidens ve Tylenchulus semipenetrans olduğu belirlenmiştir.

Anahtar sözcükler: Bitki paraziti nematodlar, sistematik, sürvey, Adana

\footnotetext{
${ }^{1}$ Bu çalışma Çukurova Üniversitesi Fen Bilimleri Enstitüsü tarafından kabul edilen yüksek lisans tezinin bölümüdür ve BAP tarafından desteklenmiştir. Ayrıca 23-27 Eylül 2012 tarihlerinde Adana'da düzenlenen Avrupa Nematoloji Kongresinde poster olarak sunulmuştur.

${ }^{2}$ Çukurova Üniversitesi, Ziraat Fakültesi, Bitki Koruma Bölümü, Sarıçam, Adana, Türkiye

${ }^{3}$ Abant İzzet Baysal Üniversitesi Ziraat ve Doğa Bilimleri Fakültesi Bitki Koruma Bölümü Gölköy Kampüsü 14280, Bolu, Türkiye

"Sorumlu yazar (Corresponding author) e-mail: ekasapoglu@cu.edu.tr

Alını̧̧ (Received): 07.01.2014 Kabul ediliş (Accepted): 28.08.2014
} 


\section{Giriş}

Nematodlar hayvanlar alemine bağlı, dünya üzerinde her türlü iklimde karasal ve sucul ortamlara uyum sağlayan; bitkiler, hayvanlar ve insanlarda parazit olarak yaşayan formlarının yanı sıra mikroorganizmalarla beslenen saprofitik grupları ile oldukça çeşitli bir canlı grubudur (Freckman \& Baldwin, 1990; Bernard, 1992; Boag \& Yeates, 1998). Dünyada hayvanlar aleminde Nematoda şubesinde 25,043 türün tanımlandığı bildirilmiştir (Zhi-Qiang Zhang, 2013). Bitki parazitleri ve serbest yaşayan grupları ile nematodlar toprakta çok hücreli mikroorganizmalardan sonra en yoğun olarak bulunan canlılar olup, Türkiye'de 2011 yılı ortalarına kadar 48 bölge ve 66 ayrı konukçuda 240 bitki paraziti nematod türü tespit edilmiştir (Kepenekci, 2012) Yapılan uluslararası surveylere dayanarak nematodlardan kaynaklanan yıllık verim kaybının \% 12,3 olduğu düşünülmekle beraber bu rakam bazı bitkilerde için \% 20'lere yaklaşmakla ve sebzelerde ise bu oranın \%80'e varabildiği bildirilmektedir (Sasser, 1986; Sasser \& Freckman, 1987). Bu kayıpların parasal açıdan karşılığı yılda 100 milyar ABD dolarını aşmaktadır (Oka et al., 2000).

Son yıllarda Türkiye'de nematoloji alanında çalışan araştırıcı sayısının artış göstermesine paralel olarak bu konuda yapılan araştırmaların da arttığı görülmektedir. Türkiye'de bitki paraziti nematodlar konusunda bugüne kadar yapılan önemli çalışmalar bulunmakta ise de hala yetersiz düzeydedir. Türkiye'deki bu zararlı grubuna ait türlerin büyük bir bölümü son yıllarda ortaya konulmuştur. Doğu Akdeniz Bölgesi'nde önemli kültür bitkilerinde bulunan nematod türleri ve dağılışları üzerine ilk kapsamlı faunistik çalışma yaklaşık 20 yıl önce gerçekleştirilmiş olup, söz konusu çalışmada 44 nematod türünün saptandığı ve bunlardan 29 adedinin Türkiye faunası için yeni kayıt, olduğu bazı nematod türlerinin değişik kültür bitkilerinde oluşturdukları popülasyon yoğunluklarının literatürde bildirilen ekonomik zarar eşiğinin üzerinde olduğu tespit edilmiştir (Elekcioğlu, 1992; Elekcioğlu \& Uygun, 1994; Elekcioğlu, 1996). Son yıllarda bölge genelinde tarımda çok önemli ilerlemeler kaydedilmiştir. Özellikle damlama sulama sistemi yaygınlaşmış, ürün yelpazesinde ciddi değişmeler olmuştur. Belirtilen açıklamalar ışığında Adana ili kültür bitkilerinde bulunan nematod faunası bakımından aradan geçen yaklaşık 20 yıllık bir sürede değişiklikler olabileceği düşünülmektedir. Bu nedenle çalışmada Doğu Akdeniz Bölgesi'nin tarım açısından en önemli illerinden biri sayılan Adana'da bulunan kültür bitkilerinde, bitki paraziti nematod türleri ve dağılımlarının belirlenmesi amaçlanmıştır.

\section{Materyal ve Yöntem}

Adana ilinde bulunan bitki paraziti nematod türlerini araştırmak amacıyla, 2010 yılı Mayıs-Ağustos döneminde Seyhan, Yüreğir, Feke, Kozan, Pozantı, Karaisalı, Yumurtalık, İmamoğlu, Ceyhan ve Karataş ilçelerinin tarım alanlarında önemli ekiliş alanlarına sahip kültür bitkilerinden toplam 140 toprak örneği alınmıştır. Örneklemenin bahsedilen ilçelerin mümkün olduğunca değişik köy ve mevkilerinde yapılmasına çalışılmıştır.

Buğday, sebze vb tek yıllık bitkilerden örnek alınırken Southey (1986)'in 40 da'ık bir alanın en az 50-60 değişik noktasından toprak örnekleri alınmış ve paçal yapılıp, etiketlemede yapıldıktan sonra laboratuara getirilmesi için hazırlanmıştır. Toprak örnekleri tarla veya bahçenin sulama sistemine göre, damlama sulama yönünden olacak şekilde, deneme alanı içinde, zikzak şekilde gidilerek, toprak sondası yardımıyla, bitkilerin olduğu alanlardan ise taç iz düşümü hizasından ve 0-30 cm'lik derinlikten alınmıştır. Laboratuara getirilen toprak örnekleri, $+4^{\circ} \mathrm{C}$ 'de buzdolabına konularak muhafaza edilmiştir. 


\section{Laboratuvar Çalışmaları}

\section{Nematodların Daimi Preparatlarının Yapılması}

Toprakta serbest ve hareketli olan nematodların elde edilmesi amacıyla Geliştirilmiş Baermann Huni Yöntemi'nin modifiye edilmiş biçimi olan Petri Yöntemi kullanılmış (Barker, 1985; Southey, 1986) ve topraktan hareketli ergin dişi ve larvalara ait bireyler elde edilmiştir. Toprak analizlerinde kist nematodları (Heterodera vb.) ergin dişileri hareketsiz olan cinslerin larvaları bulunduğunda, bu topraklarda Fenwick vb. yöntemlerle dişiler elde edilmeye çalışılmıştır.

Nematodların tür düzeyinde teşhis edilebilmesi için bunların usulüne göre öldürülerek kalıcı preparatlarının yapılması gerekmektedir. Bu amaçla topraktan elde edilerek santrifüj tüpleri içerisinde çökeltilen nematodlara ait ikinci dönem larva bireyler, $65{ }^{\circ} \mathrm{C}$ 'deki su banyosu içinde 2 dakika tutularak ölmeleri sağlanmış, TAF çözeltisi $(7 \mathrm{ml}$ formalin (\% 40 formaldehyd) $+2 \mathrm{ml}$ triethanolamin $+91 \mathrm{ml} \mathrm{saf} \mathrm{su})$ içerisinde fikse edilmiştir (Hooper, 1986). Nematodlar, fiksasyon işleminden sonra çözelti l'de (1 kısım gliserin ve $79 \mathrm{kısım}$ saf su) $35-40{ }^{\circ} \mathrm{C}$ 'de 12 saat ve çözelti Il'de (5 kısım gliserin ve $95 \mathrm{kısım} \mathrm{( \% 96)}$ ethanol) $40^{\circ} \mathrm{C}$ 'de 3 saat bekletilip gliserin içerisine alınmıştır, sıvı içerisindeki suyun tamamının çekilmesi amacıyla desikkatör içinde de bir süre bekletilmiştir (Seinhorst, 1959). Bu şekilde saf gliserin içerisine alınan nematodlar cinslerine göre ayrılarak, Wax-Ring yöntemiyle (balmumu-yüzük) (Hooper, 1986) önceden hazırlanmış olan lam üzerine alınmış, daha sonra lamel ile ısıtıcı üzerinde sabitleştirilerek tür teşhisine hazır hale getirilmiştir.

\section{Nematodların Ölçüm, Teşhis ve Çizimleri}

Nematodların teşhislerinde büyük önem taşıyan ve çalışmada kullanılan Morfometrik özellikler ve tespit edilen nematodların sinonimleri, sistematikteki yerleri vb. Siddiqi (2000)'den alınmıştır.

\section{Araştırma Sonuçları ve Tartışma}

Bu çalışmada Adana ili merkez ve ilçelerinin önemli kültür bitkilerinde bulunan bitki paraziti nematod türlerini belirlemek amacıyla alınan toprak örneklerinin incelenmesi sonucu Tylenchida, Aphelenchida ve Dorylaimida takımlarına bağlı 8 familya içinde sınıflandırılan toplam 23 adet nematod türü saptanmıştır (Çizelge 1).

Bu çalışmada tespit edilen 23 nematod türünden tespit edilmiş olup Pratylenchus cinsine ait $P$. delattrei (Luc), P. zeae (Graham), P. loosi (Loof) olmak üzere 3 tür, Helicotylenchus cinsine ait $H$. digonicus Perry, in Perry, Darling and Thorne olmak üzere 1 tür ve Scutylenchus cinsinden $S$. cylindricaudatus Ivanova olmak üzere toplam 5 türün Doğu Akdeniz Bölgesi için yeni kayıt olduğu saptanmıştır. Bu türlerden Pratylenchus delattrei (Luc)Türkiye nematod faunası için yeni tür olma niteliğini taşımaktadır. 
Çizelge 1. Adana ilinde 2010 yılında tespit edilen bitki paraziti nematod türleri ve konukçu bitkileri

\begin{tabular}{|c|c|c|c|}
\hline Tür ismi & Takım & Konukçu Bitki & Lokasyon \\
\hline Aphelenchus avenae & Aphelenchida & $\begin{array}{l}\text { Buğday, Kaysı, Bağ, Yer fıstığı, Pamuk, } \\
\text { Soya fasulyesi,Biber, Erik, Mısır }\end{array}$ & $\begin{array}{l}\text { Feke, Kozan, İmamoğlu,Yüreğir, } \\
\text { Ceyhan, Karaisalı, Karataş }\end{array}$ \\
\hline Ditylenchus myceliophagus & Tylenchida & Misır & Yumurtalık \\
\hline Helicotylenchus* digonicus & Tylenchida & Bağ, Mısır & Karaisalı, Sarıçam \\
\hline H.dihystera & Tylenchida & Bağ & Karaisalı \\
\hline H. pseudorobustus & Tylenchida & $\begin{array}{l}\text { Elma, Erik, } \\
\text { Mısır }\end{array}$ & $\begin{array}{l}\text { Sarıçam, Ceyhan } \\
\text { Karaisalı }\end{array}$ \\
\hline Rotylenchus cypriensis & Tylenchida & Şeftali, Buğday & Yumurtalık \\
\hline Rotylenchulus macrosomus & Tylenchida & $\begin{array}{l}\text { Pamuk, Bağ, Buğday, Mısır, Turunçgil, } \\
\text { Ayçiçeği }\end{array}$ & $\begin{array}{l}\text { Karaisalı, Kozan, Sarıçam, Kadirli, } \\
\text { Ceyhan }\end{array}$ \\
\hline Pratylenchus delattrei** & Tylenchida & Patlıcan & Karataş \\
\hline P. loosi* & Tylenchida & Patlıcan & Seyhan \\
\hline P. thornei & Tylenchida & Buğday, Pamuk & Pozantı, Karaisalı \\
\hline P. scribneri & Tylenchida & Soya fasulyesi & Karataş \\
\hline P. zeae* & Tylenchida & Soya fasulyesi, Patlıcan & Karataş \\
\hline Pratylenchoides alkani & Tylenchida & Ayçiçeği & Yumurtalık \\
\hline P. erzurumensis & Tylenchida & Buğday & Sarıçam \\
\hline P. leiocauda & Tylenchida & Buğday & Sarıçam \\
\hline Paratrophurus acristylus & Tylenchida & Buğday & Yumurtalık, Ceyhan, İmamoğlu \\
\hline Trophurus imperialis & Tylenchida & Ayçiçeği & Karaisalı \\
\hline Merlinius microdorus & Tylenchida & Pamuk & Kozan \\
\hline M. brevidens & Tylenchida & Buğday & Karaisalı \\
\hline $\begin{array}{l}\text { Scutylenchus* } \\
\text { cylindricaudatus }\end{array}$ & Tylenchida & Buğday & Pozantı \\
\hline Tylenchulus semipenetrans & Tylenchida & Turunçgil & $\begin{array}{l}\text { Kozan, Seyhan, İmamoğlu, } \\
\text { Yumurtalık, Sarıçam }\end{array}$ \\
\hline Xiphinema italiae & Dorylaimida & Bağ & Karaisalı \\
\hline X. pachtaicum & Dorylaimida & Bağ & Yenice \\
\hline
\end{tabular}

*Doğu Akdeniz Bölgesi nematod faunası için yeni tür

** Türkiye nematod faunası için yeni tür

\section{Tespit Edilen Türlerin Özellikleri}

Cins: Aphelenchus Bastian, 1865

Sistematikteki yeri: Nematoda Potts, 1932; Aphelenchida Siddiqi, 1980; Aphelenchina Geraert, 1966; Aphelenchoidea Fuchs, 1937 (Thorne, 1949); Aphelenchidae Fuchs, 1937 (Steiner, 1949); Aphelenchinae Fuchs, 1937

Tür: Aphelenchus avenae Bastian, 1865

Sinonim: (Hooper, 1974) Aphelenchus Agricola 1881; Paraphelenchus Agricola (1881) Flipjev, 1934; Aphelenchus (Paraphelenchus) Maupasi Micoletzky, 1922; Paraphelenchus Maupasi (Micoletzky, 1922 Bally Et Reydon, 1931; Paraphelenchus Micoletzkyi Steiner, 1941; Metaphelenchus Micoletzkyi (Steiner,1941) Steiner, 1943; Metaphelenchus Rhopalocercus Steiner, 1943; Aphelenchus Cylindricaudatus (Cobb in Steiner, 1926) Steiner, 1931;Tylenchus Cylindricaudatus Cobb in Steiner, 1926; Aphelenchus Macrobolbus Steiner, 1942; Aphelenchus Maximus, 1960; Aphelenchus Mirzai, 1960; Aphelenchus Radicicolus (Cobb, 1913) Steiner 1931, Isonchus Radicicolus Cobb, 1913; Aphelenchus Solani (Steiner, 1935) Goodey, 1951; Aphelenchoides Solani Steiner, 1935. 
Morfometrik ölçümler:

Adana populasyonu: $\mathrm{n}: 9$; $\mathrm{L}(\mathrm{mm})$ : 0,724 $\pm 0,05$ (0,604-0,822); a: $35 \pm 5,3(26,2-43,3)$; b: $5,8 \pm 1,25$

(3,9-7,6); c: $29,8 \pm 4,62(23,1-37,1)$; c': $1,75 \pm 0,52(1,1-2,6)$; Stylet $(\mu \mathrm{m}): 24 \pm 3,6(19,2-27,2)$; Kuyruk ( $\mu \mathrm{m}): 23,6 \pm 3,07(19,2-27,2) ; \mathrm{V}(\%): 74,5 \pm 4,6$ (63-78)

Goodey and Hooper (1965): n: Neotype; L(mm):0,71; a: 30; b: 5,6; c: 35; c': ?; Stylet $(\mu \mathrm{m}): 15.0$; Kuyruk ( $\mu \mathrm{m}): ? ; \mathrm{V}(\%): 78$

Konukçuları ve yayılışı: Dünya genelinde çok geniş konukçu dizisine sahip olması ve zayıf bitki paraziti olup aynı zamanda rizosferde funguslarla beslenmesi nedeniylede yaygın olarak bulunmaktadır. Örnekleme yapılan hemen her yerde Türkiye'de yoğun olarak bulunmaktadır. Türkiye'de İstanbul'da lahana, pırasa ve ıspanakta, domateste, patıcanda, biberde, patates ve fasulyede, Afrika menekşesinde, çim alanlarında, turp, mısır, ayçiçeği, kavun, karpuz ve maydanozda, Antakya, Adana ve Mersin'de turunçgil alanlarında (Citrus spp.), Çankırı, Çorum illeri çeltik ekiliş alanlarında, Diyarbakır ilinde buğday, bağ ve sebze alanlarında, Balıkesir, Bursa, Düzce, Tekirdağ, Kocaeli, Sakarya, patates ekili alanlarda bu tür saptanmıştır (Saltukoğlu, 1974; Elekcioğlu, 1992; Eken-Karataş, 2007; İmren, 2007; Erkol, 2009). Bu çalışmada kayısı, buğday, bağ, yer fıstığı, turunçgil, pamuk, erik, biber, mısır, soya fasülyesinde tespit edilmiştir.

Cins: Ditylenchus Filipjev, 1936

Sistematikteki yeri: Nematoda Potts, 1932; Tylenchida Thorne, 1949; Tylenchina Chitwood, Chitwood and Chitwood, 1950; Anguinidae Nicoll, 1935 (1926); Anguininae Nicoll, 1935 (1926)

Tür: Ditylenchus myceliophagus Goodey, 1958

Morfometrik ölçümler:

Adana populasyonu: $\mathrm{n}: 3 ; \mathrm{L}(\mathrm{mm}): 0,549 \pm 0,172$ (0,387- 0,731); a: $36,4 \pm 3,9(32,2-40) ;$ b: $5,2 \pm 0,85$

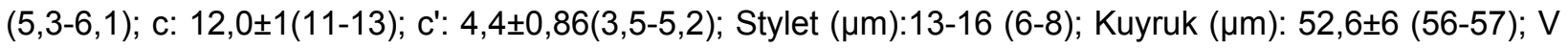
(\%): $80,3 \pm 2,4(79-83,2)$

Brzeski (1991): n: 9; L(mm): 0,544-0,708; a: 30-42; b: 4,8-7,0; c: 10,6-13,7; c': 4,0-5,2; Stylet $(\mu \mathrm{m}):$ 7-8; Kuyruk $(\mu \mathrm{m}):$ 49-59; V (\%): 78-83

Konukçuları ve yayılışı: Dünya'da İngiltere (Goodey,1958) mantarda, Hollanda ve Amerika'da da saptanmıştır. (Brzeski,1991). Türkiye'de, geniş konukçu bitki dizilimini etkilediği için birçok bölgede yaygın olarak bulunmaktadır. İstanbul Yalova'da mantar, Adana, Mersin turunçgil, patıcan, yer fıstığı, soya fasulyesi, Niğde ve Burdur'da nohut Ankara'da fasülye, bitkisinde ve Giresun, Ordu, Diyarbakır Rize'de de tespit edilmiştir (Ağdacı et al., 1990; Elekcioğlu, 1992; Kepenekci, 1999; Kepenekci \& Öztürk, 1999; Kepenekci, 2001b; Kepenekci \& Ökten, 2003; Tan, 2005). Bu çalışmada mısır ekili alanda tespit edilmiştir.

Cins: Helicotylenchus Steiner, 1945

Sistematikteki yeri: Nematoda Potts, 1932; Tylenchida Thorne, 1949; Tylenchina Chitwood, Chitwood and Chitwood, 1950; Hoplolaimidae Filipjevi, 1934 (Wieser, 1953); Rotylenchoidinae Whitehead, 1958

Tür: H. digonicus Perry, in Perry, Darling and Thorne, 1959

Sinonim: H. broadbalkiensis Yuen, 1964 
Morfometrik ölçümler:

Adana populasyonu: $\mathrm{n}: 3$; L(mm): 0,835 $\pm 0,03$ (0,811-0,875); a: $26,3 \pm 1,6(24,5-27,3) ;$ b: $4,9 \pm 0,4$

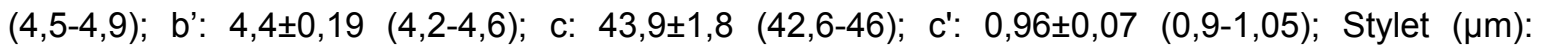
$34,8 \pm 2,7$ (37,5-32); Kuyruk ( $\mu \mathrm{m}): 19$; V (\%): 62 $\pm 0,015$ (61-64)

Kepenekci (1999): n: 20; L(mm): 0,64-0,86; a: 21,5-30,4 (24,5-27,3); b: 4,8-6,6; b': 3,6-5,3; c: 34,348,6; c': 1,0-1,5; Stylet $(\mu \mathrm{m})$ 26,33; Kuyruk $(\mu \mathrm{m}): 15,0-21,0 ; \mathrm{V}(\%): 56,8-66,4$

Konukçuları ve yayılışı: H. digonicus, Dünya'da Kanada, Etalya, Sicilya, Polonya, Rusya, Amerika Birleşik Devletlerin'de tespit edilmiştir (Sher, 1966; Thorne \& Malek, 1968). Türkiye'de de İstanbul'da da çayırlardan, sarımsak, süs bitkisi, sebze, kenevir, mantar, soğan, çim, domates, gül, nohut, fasülye, mercimek, börülce, çay, kesme çiçek, çilek, erik, zeytin, şeftali, ayçiçeği, yer fıstığı, elma ve haşhaş bitkilerinde bulunduğu bildirilmiştir. Bu çalışmada bağ ve mısır alanlarında tespit edilmiştir (Saltukoğlu, 1974; Ercan, 1976; Ediz \& Enneli, 1978; Tunçdemir, 1983; Ağdacı et al., 1990; Öztürk, 1990; Akgül \& Ökten, 1997a; Kepenekci, 1994; Akgül \& Ökten, 1997b; Kepenekci \& Akgül, 1999; Kepenekci, 1999; Kovancı et al., 2000; Akgül et al., 2000; Kepenekci et al., 2001; Kepenekci, 2001b; Kepenekci, 2001c; Kepenekci, 2001d; Kepenekci \& Öztürk, 2002b; Kepenekci \& Zeki, 2002; Akgül \& Ökten 2002; Kepenekci \& Evlice, 2003). Bu çalışmada bağ ve mısır bitkisinde bulunmuştur.

Tür: H. dihystera (Cobb, 1893) Sher, 1961

Sinonim: Tylenchus dihystera Cobb, 1893, Tylenchus olaae Cobb, 1906, Tylenchorhynchus olaae Cobb Micoletzky, 1922

Morfometrik ölçümler:

Adana populasyonu: $\mathrm{n}: 3$; $\mathrm{L}(\mathrm{mm}): 0,77 \pm 0,06(0,73-0,84) ; \quad a: 27,4 \pm 1,7(26,3-29,4) ;$ b: $4,8 \pm 0,71(4,1-$ 5,5); c: 39,1 $\pm 5,5$ (33,4-44,4); c': 1,08 $\pm 0,12(0,9-1,2)$; Stylet $(\mu \mathrm{m}): 35,7 \pm 7,5$ (27-41); Kuyruk $(\mu \mathrm{m}): 19,8 \pm 1,9$ $(18,4-22) ; \mathrm{V}(\%): 62 \pm 0,05(58-70)$

Sher (1966): n: 10; L(mm): 0,59-0,79; a: 27-35; b: 5,8-6,9; c: 35-49; c': 0,8-1,2; Stylet $(\mu \mathrm{m}): 25-$ 28; Kuyruk ( $\mu \mathrm{m})$ : ?; $\vee(\%): 60-65$

Konukçuları ve yayılışı: $H$. dihystera, Dünya'da Avustralya ve Pakistan'da tespit edilmiştir (Cobb, 1893; Shahina \& Maqbool, 1992; Knox et al., 2006). Türkiye'de ise Izmir, Eskişehir, Mersin, Ordu, Diyarbakır, Marmara Bölgesi ve Kocaeli'nde tespit edilmiştir (Borazancı, 1977; Ediz \& Enneli, 1978; Elekcioğlu, 1992; Kepenekci \& Öztürk, 1999; İmren, 2007; Tan, 2005; Erkol, 2009). Bu çalışmada bağ bitkisinde bulunmuştur.

Tür: H. pseudorobustus (Steiner, 1914) Golden, 1956

Sinonim: Tylenchus robustus var. pseudorobustus Steiner, 1914, Helicotylenchus phalerus Anderson, 1974

Morfometrik ölçümler:

Adana populasyonu: $\mathrm{n}: 2$; L(mm): 0,711-0,792; a: 20,3-24,7; b: 4,3-8,1; b': 3,8-7,2; c: 32,3-37,7; c': 1,15-1,6; Stylet $(\mu \mathrm{m}): 33-35 ;$ Kuyruk $(\mu \mathrm{m}): 22-21 ; \mathrm{V}(\%): 62-63$

Elekcioğlu (1992): n: 10; L(mm): 0,62 $\pm 0,02(0,58-0,65) ; ~ a: ~ 27 \pm 0,8(25-29) ; b: 6,6 \pm 0,2$ (6,2-7,9); b': $4,6 \pm 0,2$ (4,3-4,9); c: $38 \pm 3,1(31-45)$; c': $1,1 \pm 0,1(1,0-1,5)$; Stylet $(\mu \mathrm{m}): 26 \pm 0,2(25-27)$; Kuyruk $(\mu \mathrm{m}): 17 \pm 1,6$ (14-20); V (\%):62 $\pm 1,0(60-66)$

Konukçuları ve yayılışı: $H$. pseudorobustus, Dünya'da İsviçre ve Belçika'da tespit edildiği bildirilmiştir (Sher, 1966; Bert et al., 2003). Türkiye'de ise Eskişehir, İzmir, İstanbul, Kocaeli, Bursa, 
Mersin, Adana, Ankara, Şanlıurfa, Burdur illerinde tespit edilmiştir (Borazancı, 1977; Ediz \& Enneli, 1978; Ağdacı et al, 1990; Elekcioğlu, 1992; Elekcioğlu et al., 1994; Elekcioğlu, 1995; Kepenekci, 1999; Kepenekci \& Ökten, 2003; Evlice \& Kepenekci, 2006; Yıldız, 2007). Bu çalışmada elma, erik ve mısır bitkilerinde bulunmuştur.

Cins: Rotylenchus Filipjev, 1936

Sistematikteki yeri: Nematoda Potts, 1932; Tylenchida Thorne, 1949; Tylenchina Chitwood, Chitwood and Chitwood, 1950; Hoplolaimidae Filipjev, 1934 (Wieser, 1953); Rotylenchoidinae Whitehead, 1958

Tür: Rotylenchus cypriensis Antoniou, 1981

Morfometrik ölçümler:

Adana populasyonu; n: 2, L(mm): 0,555-0,566; a: 31,5-35,4; b: 5,9-6,8; b’:5,05-6,94; c: 34,7-39,3; c': 0,8-1,25; Stylet $(\mu \mathrm{m}):$ 20,8-24; Kuyruk ( $\mu \mathrm{m}): 14,4-16 ; \mathrm{V}(\%): 64-69$

Antoniou (1980): n: 16; L(mm): 0,60 (0,50-0,69); a: 30 (25-29) ; b: 5,7(5,3-6,4); b': ? ; c: 45(40-49); c': 1,2 (0,9-1,5); Stylet $(\mu \mathrm{m}): 23$ (21-24); Kuyruk ( $\mu \mathrm{m})$ : ?; V (\%):63,0

Konukçuları ve yayılışı: Dünya'da Pakistan'da (Shahina \& Maqbool,1992), Güney Afrika'da (Berg, E. van den,1998). Türkiye'de ise Kıbrısta, Isparta, Burdur, Akdeniz ve Karadeniz bölgesindeki elma bahçelerinde, Mersin, Antalya ve Adana illerinde ve Akdeniz bölgesindeki susam ekili alanlarda tespit edilmiştir (Antoniou, 1980; Kepenekci, 2001b; Kepenekci \& Zeki, 2002; Kepenekci \& Öztürk, 2002a; Kepenekci, 2002). Bu çalışmada şeftali ve buğday bitkisinde bulunmuştur.

Cins: Rotylenchulus Linford and Oliveira,1940

Sistematikteki yeri: Nematoda Potts, 1932; Tylenchida Thorne, 1949; Tylenchina Chitwood, Chitwood and Chitwood, 1950; Rotylenchulidae Husain and Khan 1967, (Husain, 1976); Rotylenchulinae Husain and Khan, 1967

Tür: Rotylenchulus macrosomus Dasgupta, Raski and Sher, 1968

Morfometrik ölçümler:

Adana populasyonu: $\mathrm{n}: 10 ; \mathrm{L}(\mathrm{mm}): 0,564 \pm 0,02$ (0,518-0,609); a: $32,3 \pm 4,6(27,8-42,2) ;$ b: $3,7 \pm 0,9$

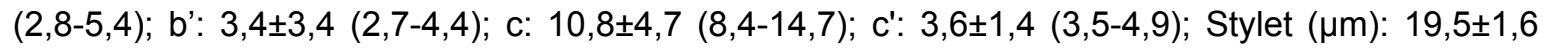

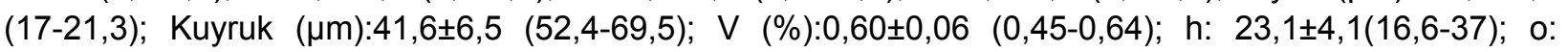
$148 \pm 0,65(0,48-2,35)$

Dasgupta ve Raski (1968): n: 21; L: 0,52-0,64; a: 30-38; b: 3,8-5,7; b': 2,9-4,3; c: 12-16; c': 3,7-5,0; Stylet $(\mu \mathrm{m})$ : 18-22; Kuyruk ( $\mu \mathrm{m}): 35-43$; V (\%): 63-68; h:? ; o: 139-188

Konukçuları ve yayılışı: Dünya'da İsrail ve İspanya'da tanımlanmıştır. Türkiye'de ise Isparta, Burdur, Şanlıurfa, Adana illerinde nohut, zeytin ve pamuk ekiliş alanlarında tespit edilmiştir (Dasgupta, Raski \& Sher, 1968; Castillo et al., 2003; Kepenekci, 2001c; Kepenekci \& Ökten, 2003; Yıldız, 2007; Gözel \& Elekcioğlu, 1996). Bu çalışmada pamuk, bağ, buğday, mısır, turunçgil, ayçiçeği bitkilerinde bulunmuştur.

Cins: Pratylenchus Filipjev, 1936

Sistematikteki yeri: Nematoda Potts, 1932; Tylenchida Thorne, 1949; Tylenchina Chitwood, Chitwood and Chitwood, 1950; Pratylenchidae Thorne, 1949 (Siddiqi, 1963); Pratylenchinae Thorne, 1949. 
Tür: P. delattrei Luc, 1958

Sinonim: P. singhi Das and Sultana, 1979, Pratylenchus portulacus Zarina and Maqbool, 1998

Morfometrik ölçümler:

Adana populasyonu: n: 2; L(mm): 0,496-0,498; a: 29-31; b: 5-5,2; b': 3,5- 4; c: 26-28,1; c': 1,3-1,5; Stylet $(\mu \mathrm{m}): 17-19,2 ;$ Kuyruk $(\mu \mathrm{m}): 17-17,6 ; \mathrm{V}(\%): 76-77$

Subramanian ve Sivakumar (1988): n: 48; L(mm): 0,43 (0,36-0,49); a: 23,7 (20,6-26,1); b: 4,8 (3,6$5,4)$; b': $3,5(3,0-4,1)$; c: 20,5 (17,3-3,3); c':1,6(1,3-2,1); Stylet $(\mu \mathrm{m}): 17(16-18) ;$ Kuyruk $(\mu \mathrm{m})$ : ?; V (\%): 77(72-79)

Konukçuları ve yayılışı: Dünya'da Güney Madagaskar, Sudan, Pakistan, Kore'de tespit edilmiştir (Saadabi, 1988; Kim \& Minagawa, 1996; Zarina \& Maqbool, 1998). Türkiye Pratylenchus cinsinin türleri arasında yeni kayıttır (Çizelge 2). Bu çalışmada patıcan bitkisinde tespit edilmiştir.

Tür: P. loosi, Loof, 1960

Sinonim: P. coffeae apud Loos, 1953

Morfometrik ölçümler:

Adana populasyonu: $\mathrm{n:} 1$; L(mm): 0,485; a:24; b: 11,8; b': 9,7; c: 25,$2 ; c^{\prime}: 3,2$; Stylet $(\mu \mathrm{m}): 11,2$; Kuyruk ( $\mu \mathrm{m}):$ 19,2; V (\%): 85

Ryss (1988): n: 10; L(mm): 0,65 (0,46-0,70); a: 33 (27-35); b:6,5 (5,6-6,8); b': 4,1 (3,5-5,0); c: 21 (17-25); c': 2,8 (2,5-3,5); Stylet $(\mu \mathrm{m})$ : 16 (15-18); Kuyruk ( $\mu \mathrm{m})$ : ?; V (\%): 83 (79-85)

Konukçuları ve yayılışı: $P$. loosi Sri Lanka, Hindistan ve Japonya'da daha önce tespit edilmiştir (Sethi \& Swarup, 1971; Seinhorst, 1977; Gotoh \& Oshima, 1963; Wu et al., 2002), Türkiye'de ise; İstanbul ve Şanlıurfa'da bu tür daha önce tespit edilmiştir (Akgül et al., 2010; Yıldız \& Elekcioğlu, 2011). Bu çalışmada patıcan bitkisinde tespit edilmiştir.

Tür: P. thornei, (Sher and Allen 1953), (Sher, 1948)

Morfometrik ölçümler:

Adana populasyonu: $\mathrm{n}: 3 ; \mathrm{L}(\mathrm{mm}): 0,55 \pm 0,03$ (0,306-0,370); a: $31,58 \pm 0,70(26,9-34,4) ; b: 5,32 \pm$

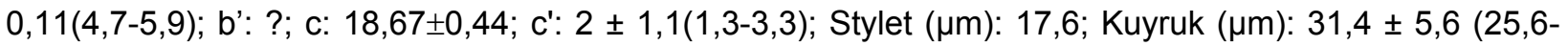
$36,8) ; \mathrm{V}(\%): 76 \pm 2,6(73-78)$

Kepenekci (1999): n: 20; L(mm): 0,56 $\pm 0,013 ; a: 27,0 \pm 0,8(24-30) ; b: 6,7 \pm 0.2(6,4-6,9) ;$ b':

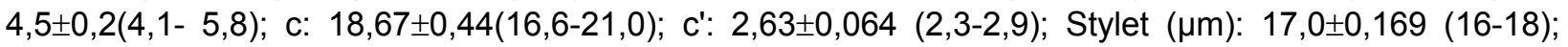
Kuyruk ( $\mu \mathrm{m}): 30,6 \pm 0,93$ (25-36); V (\%): 75,90 $\pm 0,43$ (73,8-79,2)

Konukçuları ve yayılışı: Amerika (Van Gundy et al., 1974; Lamberti, 1981), Suriye (Greco et al., 1984), Fas (Ammati, 1987) Pakistan ve Hindistan (Maqbool, 1988)'da sıkça patates, buğday, ayçiçeği ekili alanlar ile armut bahçelerinde rastlanmaktadır.

Türkiye'de ise Doğu Akdeniz Bölgesi'nde (Elekcioğlu, 1992; Elekcioğlu \& Uygun, 1994), Burdur, Aydın, Balıkesir, Çanakkale, Denizli, İzmir, Kütahya, Manisa, Muğla, Uşak (Kepenekci \& Evlice, 2003; İmren, 2007; Mısırlıoğlu \& Pehlivan, 2007), Diyarbakır, Isparta ve Burdur, Karadeniz ve Akdeniz Bölgesinde (Kepenekci \& Öztürk, 2002a; Kepenekci \& Zeki, 2002; Tan, 2005), Ankara, Karaman, Afyon, Burdur (Kepenekci \& Ökten, 2003; Evlice \& Kepenekci, 2006), Afyon, (Kepenekci \& Ökten, 1996; Kepenekci \& Evlice, 2003; Evlice \& Ökten 2008), Orta Anadolu Bölgesinde, Şanlıurfa illerinde bulunduğu bildirilmektedir (Kepenekci \& Ökten, 1999b; Yıldız, 2007; İmren 2007). Bu çalışmada buğday ve pamuk bitkisinde tespit edilmiştir. 
Tür: P. scribneri Steiner in Sherbakoff and Stanley, 1943

Sinonim: Tylenchus penetrans Cobb, 1917

Morfometrik ölçümler:

Adana populasyonu: n: 1; L(mm): 0,440; a:27,5; b: 5,2; b':4,2; c: 17,1; c': 1,7; Stylet $(\mu \mathrm{m}): 19,2$; Kuyruk $(\mu \mathrm{m}): 25,6 ; \mathrm{V}(\%): 76$

Loof (1985): n: 25; L(mm):0,58; a: 20-27; b: 4,8-7,6; b': 3,7-7,6; c: 17-18; c': 2,1-3,0; Stylet ( $\mu m$ ): 12-15; Kuyruk ( $\mu \mathrm{m}): 25-40 ; \mathrm{V}(\%): 75-79$

Konukçuları ve yayılışı: Dünya'da Mısır, Amerika, Meksika, Japonya, Hindistan, İsrail, Mısır, Nijerya, Güney Afrika'da (Loof, 1978; Brown et al., 1980; Wrather et al., 1992), Türkiye'de ise İzmir, Adana, Mersin, Bursa, Düzce ve Şanlıurfa illerinde tespit edilmiştir (Borazancı 1977; Elekcioğlu, 1992; Yıldız, 2007; Erkol, 2009). Bu çalışmada soya fasülyesinde bulunmuştur.

Tür: $P$. zeae Graham, 1951

Sinonim: Pratylenchus cubensis Razjivin and O’Relly, 1976, Pratylenchus impar Khan and Singh

Morfometrik ölçümler:

Adana populasyonu: n: 2; L(mm): 0,446-0,459; a: 31-31,8; b: 4,5-5,1; b': 3-3,5; c: 14,3-25,3; c': 22,7; Stylet $(\mu \mathrm{m}):$ 16-19,2; Kuyruk $(\mu \mathrm{m}): 17,6-32 ; \mathrm{V}(\%): 73-75$

Kepenekci (1994): n: 20; L(mm): 0,37-0,54; a: 20,4-31; b: 4,3-6,6; b': ?; c: 14,0-23,6; c': 2-3,3; Stylet ( $\mu \mathrm{m}):$ 15-18; Kuyruk ( $\mu \mathrm{m}): 19-28 ; \mathrm{V}(\%): 77,5-84,6$

Konukçuları ve yayılışı: Bu tür çoğunlukla subtropik bölgelerdeki yerfıstığı, buğdaygiller, şeker kamışı, tütün ve çim alanlarında görülebilmektedir. Pakistan'da Rosa damescana Mill.'den Pratylenchus zeae tespit edilmiştir (Saeed et al.,1988; Loof, 1991). Türkiye'de yapılan çalışmalarda, genel olarak köklezyon nematodları yaygın olup, $P$. zeae ve $P$. alleni ise birkaç alanda tespit edilmiştir (Di vito et al., 1994). Türkiye'de Pratylenchus zeae'nin Trabzon, Mersin, Burdur ve Giresun'da (Kepenekci, 2001c; Kepenekci \& Öztürk, 2002a; Kepenekci, 2003; Evlice \& Kepenekci, 2006; (Kepenekci, 2001a; Kepenekci, 2001b) bu tür tespit edilmiştir. Bu çalışmada soya fasülyesi ve patlıcanda bulunmuştur.

Cins: Pratylenchoides Winslow, 1958

Sistematikteki yeri: Nematoda Potts, 1932; Tylenchida Thorne, 1949; Tylenchina Chitwood, Chitwood and Chitwood, 1950; Pratylenchidae Thorne, 1949; Radopholinae Allen and Sher, 1967

Tür: P. alkani Yüksel, 1977

Morfometrik ölçümler:

Adana populasyonu: $\mathrm{n}: 1 ; \mathrm{L}(\mathrm{mm}): 0,720 ; \mathrm{a}: 32,1 ; \mathrm{b}: 6$; c: 28,$1 ; c^{\prime}: 1,7$; Stylet $(\mu \mathrm{m}): 24$; Kuyruk $(\mu \mathrm{m})$ : 25,6; V (\%): 58

Yüksel (1977): n: 10; L(mm): 0,97(0,82-1,21); a: 31,0 (29-35); b: 4,5 (4,5-4,9); c: 16,0 (14-17); c': 3; Stylet $(\mu \mathrm{m}): 23,3(22-25)$; Kuyruk $(\mu \mathrm{m}):$ ?; $\vee(\%): 55$

Konukçuları ve yayılışı: Dünya'da ve Türkiye'de ilk olarak Yüksel (1977) tarafından Erzurum'da, Konya, Karaman ve Nevşehir, Mersin ili (Öztürk, 1990; Elekcioğlu, 1992), Ankara'da (Kepenekci, 1994; İmren, 2007), Afyon, Marmara Bölgesi ayçiçeği ekili arazilerde (Kepenekci, 2001d; Kepenekci \& Evlice, 2003), Akdeniz Bölgesinde yer fıstığı ekili alanda ve Diyarbakır illerinde saptanmıştır (Evlice, 2005; Tan, 2005; Kepenekci \& Öztürk, 2002b). Bu çalışmada ayçiçeği ekili alanda saptanmıştır. 
Tür: P. erzurumensis Yüksel, 1977

Morfometrik ölçümler:

Adana populasyonu: n: 1; L(mm): 0,601; a: 29,3; b: 3,08; c: 14,8; c': 2,6; Stylet $(\mu \mathrm{m}): 22,3$; Kuyruk $(\mu \mathrm{m}): 20,8 ; \mathrm{V}(\%): 59$

Yüksel (1977): n: 12; L(mm): 0,600 (0,55-0,67); a: 25 (24-26); b: 4,40(3,9-4,8); c: 19(15-20); c': ?; Stylet $(\mu \mathrm{m}):$ 21(21-22); Kuyruk $(\mu \mathrm{m}): 25$ (17-33); V (\%): 59

Konukçuları ve yayılışı: Dünya'da ve Türkiye'de ilk olarak Yüksel (1977) tarafından Erzurum'da daha sonra Akdeniz Bölgesinde erikte, elmada, zeytin ve susamda ve Diyarbakır ilinde bağ alanlarında tespit edilmiştir (Kepenekci, 2001c, 2002; Kepenekci \& Öztürk, 2002a; İmren, 2007). Bu çalışmada buğday ekili alanda saptanmıştır.

Tür: P. leiocauda Sher, 1970

Morfometrik ölçümler:

Adana populasyonu: n: 2; L(mm): 0,584-0,791; a: 24,3-38; b: 4,94-6,2; c: 12,3-13; c': 2,6; Stylet $(\mu \mathrm{m}): 20,8$; Kuyruk $(\mu \mathrm{m}): 28-40 ; \mathrm{V}(\%): 57-60$

Kepenekci (1994): n: 3; L(mm): 0.57-0.78; a: 24.93-28.10; b: 4.42-6.55; c: 11.03-19.67; c': 2.543.31; Stylet $(\mu \mathrm{m})$ : 19-21; Kuyruk $(\mu \mathrm{m}): 40-52 ; \mathrm{V}(\%): 55.64-56.80$

Konukçuları ve yayılışı: Dünya'da Fransa'da Sher (1970), Türkiye'de Ankara, Osmaniye, Diyarbakır illerinde domates, buğday, armut ve bağ alanlarında tespit edilmiştir (Kepenekci, 1994; Elekcioğlu, 1996; Evlice, 2005; İmren, 2007). Bu çalışmada ayçiçeği ekili alanda saptanmıştır.

Cins: Paratrophurus Arias, 1970

Sistematikteki yeri: Nematoda Potts, 1932; Tylenchida Thorne, 1949; Tylenchina Chitwood, Chitwood and Chitwood, 1950; Telotylenchidae Siddiqi, 1960; Telotylenchinae Siddiqi, 1960

Tür: Paratrophurus acristylus Siddiqi et Siddiqui, 1983

Morfometrik ölçümler:

Adana populasyonu: $\mathrm{n}: 4$; $\mathrm{L}(\mathrm{mm})$ : 0,471 $\pm 0,08$ (0,365-0,578); a: 33,9 $\pm 8,4(26-41,2) ;$ b: $6,1 \pm 1,14$

(4,8-7,6); c: $18,5 \pm 0,98$ (17,8-19,2); c' : $2 \pm 0,14$ (1,9-2,1); Stylet ( $\mu \mathrm{m})$ : 24,4 $\pm 0,8$ (24-25,6); Kuyruk $(\mu \mathrm{m}): 40,8 \pm 1,13$ ( 40-41,6); V (\%): $59 \pm$ 10,8(47-73)

Castillo, Siddiqi and Gómez, (1989): n: 17; L(mm): 0,690 $\pm 0,04(0,616-0,766)$; a: 32,9 $\pm 1,59(29,7-$ $36,5)$; b: 5,6 \pm 0,25 (5,3-6,2); c: 17,2 $\pm 0,8$ (15,9-18,9); c': 2,5 $\pm 0,14$ (2,3-2,7); Stylet ( $\mu \mathrm{m}): 21 \pm 0,72(20-$ 22); Kuyruk ( $\mu \mathrm{m}): 40 \pm 3,05$ (34-46); V (\%): $57 \pm 1,4$ (54-59)

Konukçuları ve yayılışı: Dünyada ilk olarak Libya'da ve Fas'ta saptanmıştır (Siddiqi \& Siddiqui, 1983; Castillo et al., 1989). Türkiye'de ise Adana ilinde bu tür ilk kez buğday alanlarında, ayrıca Diyarbakır ve Şanlıurfa'da da bulunduğu bildirilmiştir (Elekcioğlu, 1996; İmren, 2007; Yıldız, 2007). Bu çalışmada buğday bitkisinde tespit edilmiştir.

Cins: Trophurus Loof, 1956

Sistematikteki yeri: Nematoda Potts, 1932; Tylenchida Thorne, 1949; Tylenchina Chitwood, Chitwood and Chitwood, 1950; Telotylenchidae Siddiqi, 1960; Telotylenchinae Siddiqi, 1960

Tür: Trophurus imperialis Loof, 1956 
Morfometrik ölçümler:

Adana populasyonu: n: 1; L(mm): 1,36; a: 32,9; b: 5,7; c: 20,3; c' :2,1; Stylet $(\mu \mathrm{m}): 24$; Kuyruk $(\mu \mathrm{m})$ : 33,6; V (\%): 58

Saltukoğlu et al. (1976): n: 5; L(mm): 0,92-1,01; a: 36-44; b: 5,7-6,2; c: 26-29; c' :1,5-1,7; Stylet $(\mu \mathrm{m}):$ 18-20; Kuyruk $(\mu \mathrm{m}): 32-38 ; \mathrm{V}(\%): 56-59$

Dünyada Hollanda'da ve Polonya'da saptanmış olup, Türkiye'de ise İstanbul, Ankara ve Adana illerinde tespit edilmiştir (Loof, 1955; Saltukoğlu et al., 1976; Elekcioğlu, 1996; Evlice, 2005). Bu çalışmada ayçiçeği bitkisinde saptanmıştır.

Cins: Merlinius Siddiqi, 1970

Sistematikteki yeri: Nematoda Potts, 1932; Tylenchida Thorne, 1949; Tylenchina Chitwood, Chitwood and Chitwood, 1950; Telotylenchidae Siddiqi, 1960; Merliniinae Siddiqi, 1971

Tür: Merlinius brevidens (Allen, 1955) Siddiqi, 1970

Sinonim: Tylenchorynchus brevidens Allen, 1955, Geocenamus brevidens (Allen) Brzeski, 1991

Morfometrik ölçümler:

Adana populasyonu: $\mathrm{n}: 2$; L(mm): 0,600-0,690; a: 29-31,2; b: 4,4-4,6; c: 10,9-12; c' : 3,1-4,0; Stylet $(\mu \mathrm{m}):$ 13-16; Kuyruk $(\mu \mathrm{m}): 36-49 ; \mathrm{V}(\%): 55-57$

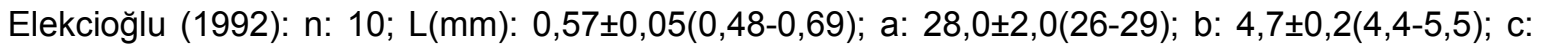

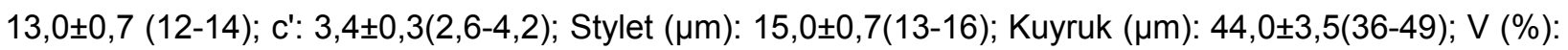
$55,0 \pm 0,7(54-57)$

Konukçuları ve yayılışı: Amerika'da Oregon'da ve İran Chabahar'da muz alanlarında olduğu bildirilmiştir (Richard, 2006; Shahbazi et al., 2009). Türkiye'de ise Aydın, Balıkesir, Çanakkale, Denizli, İzmir, Kütahya, Manisa, Muğla, Uşak, Adana buğday ve Şanlıurfa'da mercimek, pamuk, buğday alanlarında tespit edilmiştir (Gözel \& Elekcioğlu, 1996; Elekcioğlu 1992; Mısırlıŏlu \& Pehlivan, 2007; Yıldız, 2007). Bu çalışmada buğday bitkisinde tespit edilmiştir.

Tür: Merlinius microdorus (Geraert 1966) Siddiqi, 1970

Sinonim: Geocenamus microdorus Geraert, 1966

Morfometrik ölçümler:

Adana populasyonu: $\mathrm{n}: 3$; $\mathrm{L}(\mathrm{mm}): 0,63 \pm 0,02(0,60-0,64)$; a: $28 \pm 1(27-29)$; b: $5,2 \pm 0,11(5,0-5,2)$; c:

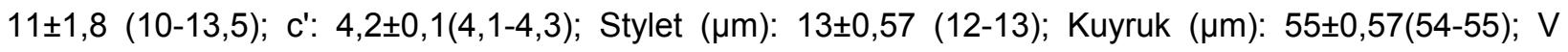
(\%):55 $\pm 4,1(52-60)$

Brzeski (1968): n: 5; L(mm): 581(485-723); a: 28 (23-39); b: 4,6 (3,9-5,6); c: 13,5 (12,8-15,2); c': 2,6 (2,2-2,9); Stylet $(\mu \mathrm{m}): 13,3(12,5-14,0)$; Kuyruk $(\mu \mathrm{m}): 46$ (32-56); V (\%): 58 (56-60)

Konukçuları ve yayılışı: Dünya'da İsviçre'de bağlarda, Daha önce yapılan çalışmalarda Adana (Balcalı)'da buğday arazisinde, Ankara'da armut bahçesinde, Şanlıurfa ilinde buğday alanlarında Merlinius microdorus saptanmıştır (Elekcioğlu, 1992, 1996; Yıldız, 2007; Evlice \& Ökten, 2008). Bu çalışmada pamuk bitkisinde tespit edilmiştir. 
Cins: Scutylenchus Jairajpuri, 1971

Sistematikteki yeri: Nematoda Potts, 1932; Tylenchida Thorne, 1949; Tylenchina Chitwood, Chitwood and Chitwood, 1950; Telotylenchidae Siddiqi, 1960; Merliniinae Siddiqi, 1971

Tür: Scutylenchus cylindricaudatus Ivanova, 1968

Sinonim: Tylenchorhynchus cylindricaudatus (Ivanova) Siddiqi, 1970

Morfometrik ölçümler:

Adana populasyonu: $\mathrm{n}: 2$; $\mathrm{L}(\mathrm{mm}): 0,772-0,736$; a: 25,5-26,8; b: 5-5,3; c: 16,4-16,6; c': 2,41-2,5; Stylet $(\mu \mathrm{m}): 22,4-24 ;$ Kuyruk $(\mu \mathrm{m}): 44,8-46,4 ; \mathrm{V}(\%): 55$

Tarjan (1973): L(mm):?; a: $0,77-0,90 ;$ b: $5-5,8 ;$ c: 14-16; c': 3,7; Stylet $(\mu \mathrm{m}): 22$-24; Kuyruk $(\mu \mathrm{m}): ? ; \mathrm{V}(\%): 57-60$

Konukçuları ve yayılışı: Bu tür Türkiye'de Isparta ve Diyarbakır'da tespit edilmiştir (Akgül \& Ökten, 1997b; Tan, 2005). Bu çalışmada buğday bitkisinde tespit edilmiştir.

Cins: Tylenchulus Cobb, 1913

Sistematikteki yeri: Nematoda Potts, 1932; Tylenchida Thorne, 1949; Tylenchina Chitwood, Chitwood and Chitwood, 1950; Tylenchulidae Skarbitovich, 1947; Tylenchulinae Skarbitovich, 1947

Tür: T. semipenetrans Cobb, 1933

Morfometrik ölçümler:

Adana populasyonu (Dişi): n: 8; Kutikula kalınlığı $(\mu \mathrm{m}): 3,9 \pm 0,5(3,0-5,3)$; Vücut şişkinliğinin oranı (\%): $46 \pm 4,5$ (35,0-58,0); Postvulval bölümün uzunluğu $(\mu \mathrm{m})$ : $38.0 \pm 3,1(28,0-50,0)$; postvulval bölümün genişliği $(\mu \mathrm{m}): 10,0 \pm 0,9(8,5-12,5)$

Inserra et al. (1988): Kutikula kalınlığı $(\mu \mathrm{m}): 3,7$ (2,9-5,65); Vücut şişkinliğinin oranı (\%): 47 (34,460,0); Postvulval bölümün uzunluğu: 40.0 (26,5-52,0); postvulval bölümün genişliği: 10,9 (9,1-13,2).

Konukçuları ve yayılışı: Adana ilindeki yaşlı turunçgil bahçelerinin birçoğunda Tylenchulus semipenetrans Cobb, 1933 köklerde ergin dişi bireyleri, toprakta ise larva bireyler tespit edilmiştir. Bölgenin iklim yapısından dolayı, geçmiş yıllardaki salma sulama sistemi, bulaşık bahçelere dikim yapılması ve bu türün 8-10 yıl toprakta yaşaması sebebiyle bölgede yoğun bulaşıklık görülmüştür. Daha önce Doğu Akdeniz bölgesinde yapılan çalışmalarda \%90'lara varan bulaşma yoğunluğu, aynı zamanda bu çalışmayı doğrulama niteliğindedir (Kıray, 1963; Elekcioğlu, 1992, 1995; Toktay \& Elekcioğlu, 2001, Elekcioğlu et al., 2013). Bu çalışmada turunçgil bahçelerinde bulunduğu görülmüştür.

Cins: Xiphinema Cobb, 1913

Sistematikteki yeri: Nematoda Potts, 1932; Dorylaimida Pearse, 1942; Dorylaimina Pearse, 1942; Longidoridea Thorne, 1935; Longidoridae Thorne, 1935 (Meyl, 1961); Xiphinematinae Dalmasso, 1969

Tür: X. italiae Meyl, 1953

Morfometrik ölçümler: 
Adana populasyonu: $\mathrm{n}: 1$; $L(\mathrm{~mm}): 2,64 ;$ a: 91,7 ; b: 11; c: 38,3 ; c': 3,30; Odontostylet $(\mu \mathrm{m}): 92,8$; Odontophore $(\mu \mathrm{m}): 60,8$; Kuyruk $(\mu \mathrm{m}): 68,8 ; \mathrm{V}(\%): 43$

Martelli et al. (1966): n: 12; L(mm): 3,04 (2,65-3,47); a: 97,0 (84-109); b: 8,1 (7,5-8,8); c: 42,0 (3847); c': 3,5 (3,2-3,9); Odontostylet $(\mu \mathrm{m})$ : 94,0 (87-99); Odontophore $(\mu \mathrm{m}): 57,0$ (55-58); Kuyruk ( $\mu \mathrm{m})$ : ?; V (\%):45 (43-48)

Konukçuları ve yayılışı: $X$. italiae İtalya, Sicilya, İsrail'de bağ ve turunçgil bahçelerinde yaygın olarak bulunmuştur (Martelli et al., 1966; Cohn, 1969). Türkiye'de Doğu Akdeniz Bölgesi'nde tespit edildiği daha önceki yapılan çalışmalarda verilmiştir (Elekcioğlu, 1992). Bu çalışmada bağ alanında bulunmuştur.

Tür: X. pachtaicum (Tulaganov, 1938) Kirjanova, 1951

Sinonim: Longidorus pachtaicus (Tulaganov, 1938); Xiphinema mediterraneum Martelli \& Lamberti 1967; syn. by Siddiqi and Lamberti, 1977; Xiphinema mediterraneum, in Cohn and Sher, 1972

Morfometrik ölçümler:

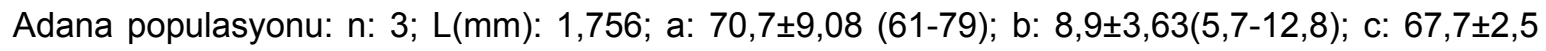

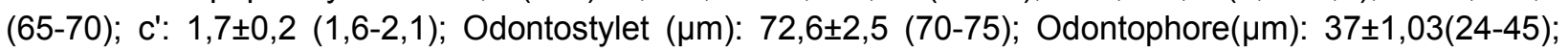
Kuyruk $(\mu \mathrm{m}): 22,4 ; \mathrm{V}(\%): 56,3 \pm 2,03(55-59)$

Lamberti ve Martelli (1971): $\mathrm{n}: 10$; L(mm): 1,8 (1,5-2,1); a: 56,0 (50-63); b: 6,5 (4,7-7,5); c: 57,0 (47-67); c': 1,7 (1,5-2,1); Odontostylet $(\mu \mathrm{m})$ : 87 (70-99); Odontophore $(\mu \mathrm{m})$ : 48 (42-51); Kuyruk ( $\mu \mathrm{m})$ : ?; V (\%): $57,0(55-58)$

Konukçuları ve yayılışı: X. pachtaicum Dünya'da; Hırvatistan'da, İtalya'da, Macaristan'da tespit edilmiştir (Samota et al., 1994; Repasi et al., 2008). Türkiye'de ise; Doğu Akdeniz Bölgesi'nde, Marmara Bölgesinde, Diyarbakır, Nevşehir ve Konya'da bağ alanlarında bulaşık olduğu tespit edilmiştir (Elekcioğlu \& Uygun, 1994; Nogay et al., 1995; Kepenekci et al., 2006; İmren, 2007). Bu çalışmada bağ alanlarında bulunmuştur.

\section{Sonuçlar ve Öneriler}

Bu çalışmanın sonucunda Tylenchida takımının Tylenchinae alt takımına bağlı; Pratylenchidae, Telotylenchidae, Anguinidae, Rotylenchulidae, Hoplolaimidae, Tylenchulidae, Aphelenchida takımına bağlı; Aphelenchidae, Dorylaimida takımına bağlı; Longidoridae familyalarından, 12 cinse bağı 23 tür saptanmıştır. Bu türlerden 5 adedi Helicotylenchus digonicus, Pratylenchus loosi, P. zeae, P. delattrei, Scutylenchus cylindricaudatus türleri Doğu Akdeniz Bölgesi nematod faunası için, Pratylenchus delattrei ise Türkiye nematod faunası için yeni kayıt niteliğindedir.

Çalışmada Rotylenchulus macrosomus'un özellikle pamuk ekili alanlarda popülasyon yoğunluğunun yüksek olduğu tespit edilmiştir. Doğu Akdeniz Bölgesi'nde farklı kültür bitkilerinde (Elekcioğlu \& Gözel, 1996) Güneydoğu Anadolu Bölgesi pamuk alanlarında yoğun olarak bulunduğu (Yıldız, 2007) bildirilmektedir. Güney İspanya'daki ticari zeytin bahçeleri için önemli bir potansiyel zararlı olabileceği belirtilmiştir, bu yüzdende belli zaman aralıklarında topraktaki popülasyonun takip edilmesi gerekliliği bildirilmiştir (Castillo et al., 2003). Bu nematodlar için yüksek sıcaklık ve nemli toprak en uygun koşullar olması nedeniylede, popülasyon seviyesinde artış olduğu bildirilmektedir (Robinson, 1994). Özellikle $R$. macrosomus bu çalışma çerçevesinde çok yaygın bir şekilde bulunmuş ve popülasyon yoğunluğunun da genellikle yüksek olduğu kaydedilmiştir. Bu türün dağılımı, konukçusu, ekonomik zararı 
üzerine yeterince çalışma olmaması nedeniyle ileriki çalışmalarda özellikle ekonomik öneminin araştırılması önerilmektedir.

Kök lezyon nematodları (Pratylenchus spp.) bitkinin köklerinden beslenerek bölgede özellikle önemli bir besin kaynağı olan buğdaylarda, ekonomik zararlara sebep olmaktadır. Doğu Akdeniz Bölgesi'nde buğday alanlarında yapılan bir çalışmada $P$. thornei \% 1,25 ile \% 32,49 oranında verim kaybına neden oldukları tespit edilmiş olup bölge için önemli bir zararlı olduğu önceden de belirtilmiştir (Elekcioğlu, 1992; Gözel, 2001). Ayrıca farklı buğday çeşitlerinde farklı yoğunlarda $P$. thornei üzerine verim denemeleri yürütülmüş, 500 birey/ $100 \mathrm{~g}$ toprak yoğunluğundaki saksılarda, Panda çeşidinde $\% 40$ oranında verim azalışı saptanmıştır (Gözel, 2001). P. thornei'nin çoğalması için bölgenin iklim koşulları ve yapısı optimum görülmektedir. Bu yüzden yoğun olarak bulunmuştur. $P$. zeae, $P$. loosi, $P$. delattrei türlerinin bölgede yeni kayıt olarak nitelendirilmesi, değişen toprak yapısı, bitki deseni ve iklim şartlarından dolayı detaylı bir sürvey çalışması yapılmasının gerekliliğini ortaya koymaktadır.

Tylenchulus semipenetrans Doğu Akdeniz Bölgesi turunçgil bahçelerinde yaygın olarak bulunmaktadır. Bu zararlının Adana ilinde bir turunçgil bahçesinde 2 yıl boyunca yürütülen çalışma sonucunda \% 10 oranında verim kaybı meydana getirdiği belirlenmiştir (Toktay \& Elekcioğlu, 2001). Popülasyon yoğunluklarının özellikle genç yaştaki turunçgil bahçelerine oranla yaşlı turunçgil bahçelerinde yoğun olduğu gözlenmiş olup, damla sulama sisteminin son yıllarda genç bahçelerde kullanıımasından ötürü, nematod bulaşıklığının azaldığı düşünülmektedir.

Xiphinema spp. türleri özelliklede bağlarda virüs taşıma özelliklerinden dolayı ekonomik olarak zararlı nematod türlerinden biridir. Xiphinema türleri Doğu Akdeniz Bölgesi (Elekcioğlu \& Uygun, 1994), Ege Bölgesi, Marmara Bölgesi (Nogay et al., 1995) ve Güneydoğu Anadolu Bölgesi (İmren, 2007) ve İç Anadolu Bölgesi'nde (Kepenekci et.al, 2006) bulaşık bulunmuştur.

Spiral nematodlar (Helicotylenchus sp.) önemli zararlı türleri içermektedir. Bölgemizde de özellikle muz yetiştiriciliği yapılan yerlerde ana zararlı durumunda olup, mücadeleyi gerektirecek bir zararlı grubudur (Elekcioğlu, 1992).

Yukarıda da özetlendiği gibi bu çalışma ile daha önce tespit edilen türlere ilave olarak 5 türün daha bu bölgede bulunduğu ortaya konmuştur. Nematodlar toprak gibi karmaşık bir ortamda yaşadıkları için birçok durumda saptanmaları bir başka ifade ile ortaya çıkarılmaları güç canlılardır. Bu nedenlerle bitki paraziti nematodların faunasının ortaya çıkarılması yoğun çalışmayı ve uzun bir süreci gerektirmektedir. Nematodlar üzerine sürvey çalışmalarının farklı zamanlarda tekrarlanması var olan ve tespit edilmeyen türlerin ortaya çıkarılmasını sağlayacaktır.

\section{Yararlanılan Kaynaklar}

Ağdacı M.., Işık, S. E., ve Erkel I., 1990. Marmara Bölgesinde kültür mantarında zararlı nematod türleri üzerine araştırmalar. Bahçe, 19 (1-2): 11-16.

Akgül, H. C., ve Ökten E., 1997. Isparta ilinde yağ gülü (Rosa domescana Mill.) yetiştirilen alanlarda farklı toprak ve derinliklerinde bulunan Tylenchida (Nematoda) Türleri Üzerinde Taksonomik Araştırmalar. Türkiye Entomoloji Dergisi, 21 (4): 269-273.

Akgül, H. C., Bayram S., ve Erdoğuş, F. D., 2010. Two new records of Turkish nematode fauna: Ditylenchus equalis and Pratylenchus pseudopratensis, Pakistan Journal of Nematolgy, 28 (2): 285-293.

Antoniou, M., 1980. Rotylenchus cypriensis sp. n. (Nematoda: Hoplolaimidae) from Cyprus. Nematologia Mediterranea, 8: 137-140.

Barker, K. R., 1985. Nematode extraction and bioassays. In: An Advanced Treatise on Meloidogyne, 2 Methodology. (Eds.: K.R. Barker, C.C. Carter and J.N. Sasser). North Carolina State University Grafics,19-39 pp. 
Berg, E. Van den.,1998. New records and notes on known species of Hoplolaimidae (Nemata) in South Africa. Journal of Nematode Morphology and Systematics, 1 (1): 29-46

Bernard, E. C., 1992. Soil Nematode Biodiversity Biology and Fertility of Soils, 14: 99-103.

Boag, B., and Yeates, G. W., 1998. Soil nematode biodiversity in terrestrial ecosystems. Biodiversity and Conservation, 7 (5): 617-630.

Bongers, T., Ferris, H., 1999. Nematode community structure as a bioindicator in environmental monitoring. Trends in Eceology and Evolution, 14: 224-228.

Borazancı, N., 1977. İzmir ili ve civarındaki seralarda yetiştirilen süs bitkilerinde, bitki paraziti nematod türlerinin tespiti ve zarar dereceleri üzerinde çalışmalar. E. Ü. Ziraat Fakültesi, Fen Bilimleri Enstitütüsü, Uzmanlık tezi. $180 \mathrm{~s}$.

Brown, M. J., Riedel R. M., and Rowe R. C., 1980. Species of Pratylenchus associated with Solanum tuberosum cv Superior in Ohio. Journal of Nematology, 12 (3): 189-192.

Brzeski, M. W., 1968, Taxonomy of Geocenamus Thorne and Malek, 1968 (Nematoda: Belonolaimidae). Nematologica, 37: 125-173.

Brzeski, M. W., 1991. Review of the genus Ditylenchus Filipjev, 1936 (Anguinidae). Revue de Nematologie, 14 (1): 9-59.

Castillo, P., Siddiqi, M. R. A., and Gomez-Barcina, 1989. Studies on the genus Paratrophurus Arias (Nematoda: Tylenchida) with descriptions of two new species. Nematologia Mediterranea, 17: 83-95.

Castillo, P., Vovlas N., and Troccoli A., 2003, The reniform nematode, Rotylenchulus macrosoma, infecting olive in Southern Spain. Journal of Nematology, 5 (1): 23-29.

Dasgupta, R., Raski, D. J., and Shers, A., 1968. A revision of the genus Rotylenchulus Linford and Oliveira, 1940 (Nematoda: Tylenchidae). The Proceedings of the Helminthological Society of Washington, 25 (2): $169-192$.

Eken-Karataş, S., 2007. Çankırı Çorum illeri çeltik ekiliş alanlarındaki (Oryza sativa L.) bitki paraziti nematod türlerinin taksonomik özellikleri, yoğunlukları ve yaygınlıkları üzerine araştırmalar, Gazi Ü. Biyoloji Bölümü, Fen bilimleri Enstitüsü, Yüksek Lisans Tezi. 126 s.

Elekcioğlu, İ. H., 1992. Untersuchungen zum Auftreten and zur Verbreitung Phytoparasitaerer Nematoden in den landwirtschaftlichen Hauptkulturen des ostmediterranen Gebietes der Türkei. PLITS, 10 (5): 120 p.

Elekcioğlu, İ. H., and Uygun, N., 1994. Occurrence and distribution of plant parasitic nematodes in cash crop in Eastern Mediterrenean Region of Türkiye. Proceedings of 9th Congress of The Mediterranean Phytopathological Union, Kuşadası Aydın, Türkiye, 409-410.

Elekcioğlu, İ. H., 1995. Plant parasitic nematodes associated with citrus in the East Mediterranean Region of Turkey. Journal of Turkish Phytopathology, 24 (1): 29-37.

Elekcioğlu, İ. H., 1996. Türkiye ve Doğu Akdeniz Bölgesi için yeni bitki paraziti nematod türleri. Türkiye III. Entomoloji Kongresi Bildirileri, Ankara. 502-509.

Elekcioğlu, İ. H., ve Gözel, U., 1996. Balcalı (Adana)'da buğdayda bulunan bitki paraziti nematod türlerinin popülasyon dalgalanmalarının araştırılması. Türkiye 3. Entomoloji Kongresi Bildirileri, 24-28 Eylül 1996, Ankara. 388-395.

Elekcioğlu, İ. H., Toktay, H., Kasapoğlu, E. B., İmren, M., 2013. Studies on the Citrus Nematode, Tylenchulus semipenetrans, Cobb 1913 in the East Mediterranean Region of Turkey. Integrated Control in Citrus Fruit Crops, 7-9 May 2013 Adana, p. 43.

Erdal F., Durmuş F., Kepenekci İ., Ökten E., 2001. Türkiye'de tahıl, baklagil, endüstri bitkileri, sebze, meyve, bağ ve turunçgil alanlarında saptanan Tylenchida (Nematoda) türlerinin ilk listesi. Türkiye Entomoloji Dergisi. 25 (1): 49-64

Erkol, D., 2009. Marmara bölgesi serbetçiotu (Humulus lupulus I.) ve patates (Solanum tuberosum I.) ekiliş alanlarında bulunan nematoda türleri üzerinde taksonomik araştırmalar. Ankara Üniversitesi Ziraat Fakültesi, Fen Bilimleri Enstitüsü, Doktora Tezi. $181 \mathrm{~s}$.

Evlice, E., 2005. Ankara ili'nde armut (Pyrus communis L.) bahçelerinde bulunan Tylenchida (Nematoda) türleri üzerinde faunistik ve taksonomik araştırmalar, Ankara Üniversitesi, Ziraat Fakültesi, Fen Bilimleri Enstitüsü, Yüksek Lisans Tezi. 168 s. 
Evlice, E., ve Ökten, M. E., 2008. Ankara ili armut (Pyrus communis L.) bahçelerinde saptanan Tylenchida (Nematoda) takımına ait bitki paraziti nematodlar. Bitki Koruma Bülteni, 48 (4):

Freckman, D.W., and Baldwin, J. G., 1990. Nematoda In Soil Biology Guide. (Dindal, D. L., Wiley J., Sons Inc., Eds.) New York. 155-200.

Gaugler, R., Bilgrami, A. L., 2004. Nematode Behaviour. New Brunswick, New Jersey, USA. 3-7.

Goodey, J. B., 1958. Ditylenchus myceliophagus n. sp. (Nematoda: Tylenchida). Nematologica, 3: 91-96.

Goodey, J. B., and Hooper, D. J., 1965. A neotype of Aphelenchus avenae Bastian, 1865 and the rejection of Metaphelenchus Steiner, 1943. Nematologica, 2: 55-65.

Gotoh, A., and Oshıma, Y., 1963. Pratylenchus species and their geographical distribution in Japan (Nematoda: Tylenchida). Japanese Journal of Applied Entomology and Zoology. 7: 187-199.

Gözel, U., 2001. Doğu Akdeniz Bölgesi buğday alanlarında bulunan bitki paraziti nematod türleri üzerinde araştırmalar. Çukurova Üniversitesi Ziraat Fakültesi, Fen Bilimleri Enstitüsü, Doktora Tezi, $129 \mathrm{~s}$.

Gözel, U., ve Elekcioğlu, İ. H., 1996. Balcalı (Adana)'da bulunan bitki paraziti nematod türlerinin popülasyon dalgalanmalarının araştııılması, Türkiye 3. Entomoloji Kongresi Bildirileri, 24-28 Eylül 1996, Ankara. 388-395.

Hooper D. J., 1986. Extraction of Free Living Stages From Soil. In: Southey, J. F. (ed.). Labarotory Methods for Work with Plant and Soil Nematodes. Her Majesty's Stationery Office, London: 5-30.

İmren, M., 2007. Diyarbakır ili buğday, sebze ve bağ alanlarında önemli bitki paraziti nematod türlerinin belirlenmesi, Ç. Ü. Ziraat Fakültesi, Fen Bilimleri Enstitüsü, Yüksek Lisans Tezi, 116 s.

Inserra, R. N., Esser, R.P., O'bannon, J. H., 1988. Identification of Tylenchulus species. Nematology Circular, No. 153. Fla. Dept. Agric. \& Consumer Serv. Division of Plant Industry.

Kepenekci, İ., 1994. Beypazarı (Ankara) ilçesinde havuç (Daucus carota L.) ile münavebeye giren domates (Lycopersicum esculentum Mill.) ekim alanlarındaki Tylenchida (Nematoda) türleri üzerinde taksonomik araştırmalar. A. Ü. Ziraat Fakültesi, Fen Bilimleri Enstitüsü, Yüksek Lisans Tezi. 236 s.

Kepenekci, İ., 1999. Orta Anadolu Bölgesinde yemeklik baklagil ekiliş alanlarındaki Tylenchida (Nematoda) türleri üzerinde taksonomik araştırmalar. A. Ü. Ziraat Fakültesi, Fen Bilimleri Enstitüsü, Doktora Tezi. 270 s.

Kepenekci, İ., ve Öztürk, G., 1999. Doğu Karadeniz Bölgesindeki kivi (Actinidia deliciosa cv. Hayward) bahçelerinde saptanan Tylenchida (Nematoda) takımına ait bitki paraziti nematodlar. Türkiye 3. Ulusal Bahçe Bitkileri Kongresi Bildirileri, Ankara. 892-896.

Kepenekci, İ., 2001a. Plant parasitic nematodes of Tylenchida (Nematoda) associated with walnut (Juglans regia L.) and chestnut (Castanea sativa Miller) orchards in the Black Sea Region. Tarım Bilimleri Dergisi, 7 (2): 101 105.

Kepenekci, İ., 2001b. Plant parasitic nematodes of Tylenchida (Nematoda) associated with stone fruits (apricots and peaches) in Southern Turkey. Pakistan Journal of Nematology, 19 (1-2): 49-61.

Kepenekci, İ., 2001c. Preliminary list of Tylenchida (Nematoda) associated with olive in the Black Sea and the Mediterranean Regions of Turkey. Nematologia Mediterranea, 29: 145-147.

Kepenekci, İ., 2001d. Marmara Bölgesinde ayçiçegi (Helianthus annuus L.) ekiliş alanlarındaki Tylenchida (Nematoda) türleri üzerinde taksonomik araştırmalar. Bitki Koruma Bülteni, 41 (3-4): 101-134.

Kepenekci, İ., 2002. Plant parasitic nematodes species of Tylenchida (nematoda) associated with sesame (Sesamum indicum I.) growing areas in the Mediterranean region of Turkey. Turkish Journal of Agriculture and Forestry, 26 (6): 323-330.

Kepenekci, İ., ve Öztürk, G., 2002. Plant parasitic nematodes of Tylenchida (Nematoda) associated with groundnut (Arachis hypogaea L.) fields in the Mediterranean Region of Turkey. Phytoparasitica, 30 (3): 288-289.

Kepenekci, I., and Zeki, C., 2002. Nematodes of Tylenchida (Nematoda) associated with apple in Turkey. Pakistan Journal of Nematology, 20 (1): 61-63.

Kepenekci, İ., ve Evlice, E., 2003. Afyon, Burdur ve Isparta illerindeki haşhaş (Papaver somniferum L.) ekiliş alanlarında saptanan Tylenchida (Nematoda) takımına ait bitki paraziti nematodlar. Türkiye 5. Tarla Bitkileri Kongresi Bildirileri, 2: 584-586. 
Kepenekci, İ., ve Ökten, E., 2003. Orta Anadolu Bölgesi'nde nohut (Cicer arietinum L.) ve mercimek (Lens esculenta Moench) ekiliş alanlarındaki Tylenchida (nematoda) türleri üzerinde taksonomik araştırmalar. Türkiye 5. Tarla Bitkileri Kongresi Bildirileri, Diyarbakır, 2: 602-604.

Kepenekci, İ., Evlice, E., and Toktay, H., 2006. Plant parasitic nematodes associated with Vineyards (Vitis vinifera L.) in the Central Anatolia region of Turkey. Proceedings of XXVIII. Symposium of the European Society of Nematologists, Blagoevgrad, Bulgaria.

Kıray, Y., 1963. Turunçgil Nematodu (Tylenchulus semipenetrans Cobb, 1913). Yaşayışı ve Mücadelesi. Kemal Matbaası, Adana. $8 \mathrm{~s}$.

Kovancı, B., Akgül, H.C., Gençer, N.S. ve Kovancı, O.B., 2000. Bursa ili çilek ekiliş alanlarında saptanan bitki paraziti nematod türleri. Türkiye 4. Entomoloji Kongresi Bildirileri, $547 \mathrm{~s}$.

Lamberti, F. and Martelli, G. P., 1971. Notes on Xiphinema mediterraneum (Nematoda: Longidoridae). Nematologica, 17: 75-81.

Loof, P. A. A., 1978. The genus Pratylenchus Filipjev, 1936 (Nematoda: Pratylenchidae): A review of its anatomy, morfology, distribution, systematics and identification. Sveriges Lantbruk-suniveritet Vaxskyddsrapporter 5: 112.

Loof, P. A. A., 1985. Pratylenchus scribneri. ClH Descriptions of Plant Parasitic Nematodes., Commonwealth Agricultural Bureaux. St Albans, UK. 8 (110): 4 p.

Martelli, G. P., Cohn, E., and Dalmasso, A., 1966. A redescription of Xiphinema italiae Meyl, 1953 and its relationships to Xiphinema arenariunz Luc et Dalmasso, 1963 and Xiphinenza conurum Siddiqi, 1964. Nematologica, 12: 183-194.

Mısırlığlu, B. ve Pehlivan, E., 2007. Ege ve Marmara Bölgeleri buğday ekiliş alanlarında bulunan önemli bitki paraziti nematodlar, Türkiye II. Bitki Koruma Kongresi Bildirileri, 27-29 Ağustos 2007, Isparta. $250 \mathrm{~s}$

Nogay, A., Ağdacı, M. ve Gürsoy, Y. Z., 1995. Marmara bölgesinde bağlarda ve amerikan asma anaçlıklarında görülen virüs hastalıklarının ve vektörlerinin saptanması üzerine araştırmalar. VII. Türkiye Fitopatoloji Kongresi Bildirileri. 247-251.

Öztürk, G., 1990. Konya, Karaman ve Nevşehir illeri soğan (Allium cepa L.) ekiliş alanlarında bulunan Tylenchida takımına ait bitki paraziti nematod türleri üzerinde taksonomik araştırmalar. A. Ü. Ziraat Fakültesi, Fen Bilimleri Enstitüsü, Doktora Tezi. 214 s.

Repasi, V., Agostinelli, A., Nagy, P., Coiro, M., Hecker, K., and Lamberti, Distribution and morphometrical characterization of Xiphinema pachtaicum, X. simile, X. brevicollum from Hungary, Journal of Helminthology, 45 (2): 96-102.

Richard, W., 2006. Geocenamus brevidens associated with reduced yield of no-till annual spring wheat in Oregon. Plant Disease, 90 (7): 885 - 890.

Robinson, A. F., 1994. Movement of ve nematode species through sand subjected to natural temperature gradient uctuations. Journal of Nematology, 26: 46-58.

Ryss, A.Y., 1988. World Fauna of the root parasitic nematodes of the family Pratylenchidae (Tylenchida). Leningrad, USSR, Nauka. 367 p.

Samota, D., Ivezic, M., and Raspudic, E., 1994. Ecology of Xiphinema vuittenezi and Xiphinema pachtaicum in vineyards of North-East Croatia, EPPO Bulletin, 24 (2): 375-381.

Saltukoğlu, M. E., 1974. A taxonomical and morphological study of Tylenchida (Nematoda) from the Istanbul area (Turkey). State University of Gent, Belgium. Doctoral thesis. 88 p.

Saltukoğlu, M. E., Geraert, E. and Coomans, A., 1976. Some Tylenchida from the Istanbul area (Turkey). Nematologia Mediterranea, 4: 139-153.

Sasser, J.N. \& Freckman, D.W. 1987. A world perspective on nematology: the role of the society. In J.A.Veech \& D.W. Dickson, eds. Vistas on nematology, p. 7-14. Hyattsville, Maryland, USA, Society of Nematologists.

Seinhorst, J.W., 1959. A rapid Method for the Transfer of Nematodes from Fixative to Anhydrous Glycerin. Nematologica, 4: 67-69.

Seınhorst, J. W., 1977. Pratylenchus loosi. CIH Descriptions of Plant Parasitics Nematodes, Commonwealth Agricultural Bureaux, St Albans, UK. 7 (98): 2 p. 
Sethi, C. L., and Swarup, G., 1971. Plant parasitic nematodes of North- Western India . III. The genus Pratylenchus. Indian Phytopathology, 24: 410-412

Shahbazi, H., Mohammad, D., Barooti, S., 2009. Collecting and identifiy of plant parasitics nematodes of banana in Chabahar. Proceedings of XXVIII. Congresso Brasileiro de Nematologia II. Congresso Internacional de Nematologia Tropical. 33 (4): 334.

Shahina, F. and Maqbool, M.A.,1986. Four new species of the family Hoplolaimidae: (Nematoda) with notes on Rotylenchus cypriensis Antoniou from Pakistan. Nematology Mediterrenaen, 14: 117-128.

Shahina, F. and Maqbool, M.A., 1992. Nematodes from Banana Fields in Sindh with Morphometric Data on Nine Species with Six Representing New Records of Occurence in Pakistan. Pakistan Journal of Nematology, 10 (1): 23-39.

Sher, S. A., 1966. Revision of the Hoplolaiminae (Nematoda) VI. Helicotylenchus Steiner 1945. Nematologica, 12: 156.

Sher, S. A., 1970. Revision of the Genus Pratylenchoides Winslow 1958 (Nematoda: Tylenchoidae). Proceedings of the Helminthological Society of Washington, 37 (2): 154-166.

Siddiqi, M. R., and Siddiqui, Z. A., 1983. Paratrophurus acristylus sp. n. and Tylenchorhynchus graciliformis sp. n. (Nematoda: Tylenchida) from wheat fields in Libya. Proceedings of the Helminthological Society of Washington, 50: 301-304.

Siddiqi, M. R., 2000. Tylenchida parasites of plants and insects. Cabi Publishing, UK. 110-117 p.

Southey, J. F., 1986. Principles of sampling for nematodes. In: (Southey, J. F. Eds.) Labarotory Methods for Work with Plant and Soil Nematodes. Her Majesty's Stationery Office, London. pp. 1-4.

Subramanian, S., and Sivakumar, C. V., 1988. Morphometric and allometric variations in Pratylenchus delattrei Luc, 1958 from Tamil Nadu, India. Indian Journal of Nematology, 18: 392-394.

Tan, A., 2005. Diyarbakır ili kavun (Cucumis melo L.) ve karpuz (Citrullus lunatus Thunb.) ekiliş alanlarında Tylenchida (Nematoda) türleri üzerinde taksonomik araştırmalar, Ankara Üniversitesi, Fen Bilimleri Enstitüsü. Doktora Tezi, $203 \mathrm{~s}$.

Tarjan, A.C., 1973. A synopsis of the genera and species in the Tylenchorhynchinae (Tylenchoidea, Nematoda). Proceedings of the Helminthological Society of Washington, 40: 123-144.

Thorne, G., and Malek, R. B., 1968. Nematodes of Northern Great Plains, Part 1, Tylenchida (Nematoda: Secernentea). Technical Bulletin South Dakota Agricultural Experiment Station, 31 p.

Toktay, H., ve Elekcioğlu, İ.H., 2001. Doğu Akdeniz Bölgesi'nde Tylenchulus Semipenetrans Cobb (Nemata, Tylenchulidae)'ın popülasyon dalgalanması ve Washington Navel portakal çeşidinde verime olan etkisinin belirlenmesi. Türkiye 4. Entomoloji Kongresi Bildirileri. Aydın. 237-246 s.

Wrather, J.A., Niblack L. and Milam M. R., 1992. Survey of plant-parasitic nematodes in Missouri cotton fields. Journal of Nematology, 24 (4): 779-782

Wu, H.Y., Tsay, T.T., and Lın, Y.Y., 2002. Identification and biological study of Pratylenchus spp. isolated from the crops in Taiwan. Plant Pathology Bulletin, 11: 123-136.

Yıldız, Ş., 2007. Şanlıurfa İlinde nematod faunası ve biyoçeşitliliği üzerine araştırmalar, Çukurova Üniversitesi, Ziraat Fakültesi, Fen bilimleri Enstitüsü. Doktora tezi, $102 \mathrm{~s}$.

Yıldız, Ş., ve Elekcioğlu İ. H., 2011. Şanlıurfa ilinde tarımsal ve doğal alanlarda nematod biyoçeşitliliği, Türkiye Entomoloji Dergisi, 35 (2): 381-394

Yüksel, H., 1977. Pratylenchoides alkani n. sp. and P. erzurumensis n. sp. (Nematoda: Tylenchoidea) from soil in Turkey. Proceedings of the Helminthological Society of Washington, 44 (2): 185-188.

Zarina, B., and Maqbool, M. A., 1998. Descriptions and observations on two new and two known species of the genus Pratylenchus Filipjev, 1936 (Nematoda: Pratylenchidae) from Pakistan. Pakistan Journal of Nematology, 16: 13-24.

Zhi-Qiang Zhang, 2013. Animal biodiversity: An update of classification and diversity in 2013. Zootaxa, 3703 (1): 005-011. 